\title{
Phylogenetic analysis and expression profiling of the Klotho gene family in the short-lived African killifish Nothobranchius furzeri
}

\author{
Gordin Zupkovitz $^{1} \cdot$ Julijan Kabiljo $^{1} \cdot$ David Martin $^{1} \cdot$ Sylvia Laffer ${ }^{1} \cdot$ Christian Schöfer $^{1} \cdot$ Oliver Pusch $^{1}$ (I)
}

Received: 20 April 2018 / Accepted: 16 August 2018 / Published online: 3 September 2018

(C) The Author(s) 2018

\begin{abstract}
Members of the Klotho gene family have been identified as modulators of the aging process. Deletion of $\alpha k l o t h o$ in the mouse results in a syndrome resembling rapid human aging. Conversely, overexpression of $\alpha$ klotho extends mammalian lifespan. Here, we identify klotho orthologs in the vertebrate aging model Nothobranchius furzeri and provide a detailed spatio-temporal expression profile of both paralogs, $\alpha$ and $\beta k l o t h o$, from embryogenesis until old age spanning the entire life cycle of the organism. Specifically, we observe low levels of expression of both paralogs during embryogenesis followed by a significant transcriptional induction as development proceeds. In adult killifish, $\alpha$ klotho is predominantly expressed in the liver, the kidney, and the developing pharyngeal teeth. Particularly high levels of $\alpha$ Klotho protein were identified in the kidney tubules, closely resembling mammalian expression patterns. Prominent $\beta k l o t h o$ expression was detected in the killifish intestine and liver. Overall, qRT-PCR analysis of Klotho members as a function of age revealed steady transcript levels, except for $\beta k l o t h o$ expression in the liver which was significantly downregulated with age. This spatio-temporal expression profiling may serve as a useful starting point to further investigate the distinct physiological roles of Klotho members during the aging process.
\end{abstract}

Keywords Klotho $\cdot$ African killifish $\cdot$ Nothobranchius furzeri $\cdot$ Aging

\section{Introduction}

Members of the Klotho gene family, including $\alpha$ and $\beta k l o t h o$, have been described to play a critical role in the regulation of the aging process. The aklotho gene, named after the Greek goddess Klotho who spins the thread of life, was identified in 1997 as a gene mutated in a mouse strain that exhibited short lifespan and complex phenotypes resembling human premature

Communicated by Matthias Hammerschmidt

Electronic supplementary material The online version of this article (https://doi.org/10.1007/s00427-018-0619-6) contains supplementary material, which is available to authorized users.

Oliver Pusch

oliver.pusch@meduniwien.ac.at; https://

anatomieundzellbiologie.meduniwien.ac.at

Gordin Zupkovitz

gordin.zupkovitz@meduniwien.ac.at

Julijan Kabiljo

julijan.kabiljo@meduniwien.ac.at

David Martin

david.martin@meduniwien.ac.at aging syndrome (Kuro-o et al. 1997). Conversely, overexpression of the $\alpha$ klotho gene in mice suppresses aging and extends lifespan (Kurosu et al. 2005). $\alpha$ Klotho is a type I transmembrane protein that is primarily expressed in the brain and kidney (Kuro-o et al. 1997). The $\alpha$ Klotho protein exists in both membrane-bound and secreted forms exerting distinct functions. Membrane Klotho interacts with fibroblast growth factor (FGF) receptors to form high-affinity receptors for FGF23

Sylvia Laffer

sylvia.laffer@meduniwien.ac.at

Christian Schöfer

christian.schoefer@meduniwien.ac.at

1 Center for Anatomy \& Cell Biology, Medical University of Vienna, Schwarzspanierstr. 17, 1090 Vienna, Austria 
(Urakawa et al. 2006) regulating phosphate metabolism. In addition to functioning as a co-receptor, the secreted form serves as a humoral factor. The secreted protein can enter the circulation via two pathways: either through an alternative splicing event or through shedding of the extracellular domain of the transmembrane protein by membrane-anchored proteases releasing the secreted form into blood, urine, and cerebrospinal fluid (Imura et al. 2004). Database mining identified $\beta k$ lotho as a gene homologous to $\alpha$ klotho (Ito et al. 2000). Similar to $\alpha$ klotho, $\beta$ klotho encodes a single-pass transmembrane protein that forms complexes with FGF receptors (Ogawa et al. 2007). Despite the high structural similarity between $\alpha$ klotho and Bklotho, their expression profiles vary considerably, with $\beta$ klotho being predominantly expressed in the liver, pancreas, and adipose tissue of adult mice (Ito et al. 2000).

In the last decade, the turquoise killifish Nothobranchius furzeri has emerged as an exciting new model system for experimental aging research because it uniquely combines an exceptional short lifespan with vertebrate-specific features that are missing from currently used non-vertebrate organisms (Harel et al. 2015). With a lifespan of 4-6 months, $N$. furzeri is to date the vertebrate species with the shortest lifespan that can be bred in the laboratory (Valdesalici and Cellerino 2003). Despite their short lifespan, the fish show typical agingrelated phenotypes such as physiological and cognitive decay, expression of aging-related biomarkers, decline in fertility, and cancerous lesions (Di Cicco et al. 2011). Additionally, $N$. furzeri is also sensitive to environmental changes that affect aging in other species, such as temperature (Valenzano et al. 2006a), caloric restriction (Terzibasi et al. 2009), and a resveratrol-enriched diet (Valenzano et al. 2006b). Only very recently, the successful completion of a reference genome for the short-lived turquoise killifish has been reported (Reichwald et al. 2015; Valenzano et al. 2015). In the present study, we identified orthologs of the Klotho gene family in Nothobranchius furzeri and provide a detailed spatiotemporal expression analysis of $\alpha$ klotho and $\beta$ klotho covering the entire lifespan of this organism.

\section{Materials and methods}

\section{Ethics statement}

All killifish experiments and procedures were performed according to the "Principles of laboratory animal care" as well as to ethical standards of the Ethics Committee of the Medical University of Vienna.

\section{Killifish care and maintenance}

All experiments were performed on $N$. furzeri of the GRZ strain (kindly provided by Dario Valenzano, MPI
Cologne). The strain was originally collected in Zimbabwe in 1968, has an extremely short lifespan of about 16 weeks, and is highly inbred. For mating and breeding adult, animals were group and housed in a recirculation system with integrated multi-phase filtration. Fish were fed twice daily with live red blood worms (Chironomus) and maintained at $28{ }^{\circ} \mathrm{C}$ on a 12 -h light/ dark cycle. Eggs were collected twice a week. Fertilized eggs were incubated in 1× Yamamoto's embryo solution with daily monitoring. Once eyes were recognizable, embryos were transferred to peat moss until ready to hatch. Fry was fed on freshly prepared brine shrimp (Artemia nauplii) until 3-4 weeks of age. Adult animals subject to further analyses were kept in a stand-alone overflow custom-made system with a fish density of one fish per 2.8-1 tank. Water changes were performed every other day. For tissue collection and preparation, fish were euthanized with MS-222 and cooled on crushed ice for $5 \mathrm{~min}$ before dissection. Whole fish or dissected organs were further processed for IHC or snap-frozen in liquid nitrogen and stored at $-80{ }^{\circ} \mathrm{C}$ for RNA isolation.

\section{Survival curve}

To analyze survival rates, two independent hatches consisting of 52 and 61 (total 113) fish were combined. Mixed-sex groups were set up at 5 weeks of age when animals showed first signs of sex dimorphism. Initial fish densities in these trials were eight animals per 25-1 tank. Tanks were inspected twice a day and dead animals were instantly recorded and removed. Based on these data, survival rates were computed on a weekly basis. During the trial, we did not adjust population density caused by declining group size. Survival is presented as percentage of alive fish at a certain age per total number of fish.

Fig. 1 a Genomic organization of killifish orthologues of klotho. Boxes and lines represent exons and introns with the length of bp indicated. Translation initiation and termination codons are shown above. Gray lines specify $5^{\prime}$ UTR and $3^{\prime}$ UTR. Arrows denote the approximate binding sites of primers used for cloning and qRT-PCR. The predicted structural organization of the killifish Klotho proteins is illustrated below their respective genomic composition. Numbers above arrows indicate amino acid position. The proteins share a common structure with human and mouse homologs, consisting of an extracellular domain with two internal repeats (KL1 and KL2), a transmembrane domain (M), and a short intracellular part. b Phylogenetic tree based on protein sequences from the Klotho family. The tree was generated by the MaximumLikelihood algorithm. Klotho protein from the nematode C. elegans was used as an outgroup. We considered the following species: human (Homo sapiens), mouse (Mus musculus), frog (Xenopus tropicalis), chicken (Gallus gallus) zebrafish (Danio rerio), spotted gar (Lepisosteus oculatus), medaka (Oryzias latipes), platyfish (Xiphophorus maculatus), killifish (Nothobranchius furzeri), and coelacanth (Latimeria chalumnae) 


\section{Cloning of killifish aklotho and $\beta$ klotho}

Killifish cDNA was synthesized from total RNA from 5week-old fish using a combination of Oligo-dT and random primer with the GoScript Reverse Transcription System
(Promega). To clone full-length killifish, $\alpha$ and $\beta k$ lotho PCR was performed with gene-specific primer pairs $\alpha \mathrm{KL}-\mathrm{F}, \alpha \mathrm{KL}$ $\mathrm{R}$ and $\beta \mathrm{K} 1-\mathrm{F}, \beta \mathrm{KL}-\mathrm{R}$ (Fig. 1a, listed in supplementary materials) using Q5 High-Fidelity DNA Polymerase (NEB). PCR products were cloned into the pJET1.2 blunt cloning vector
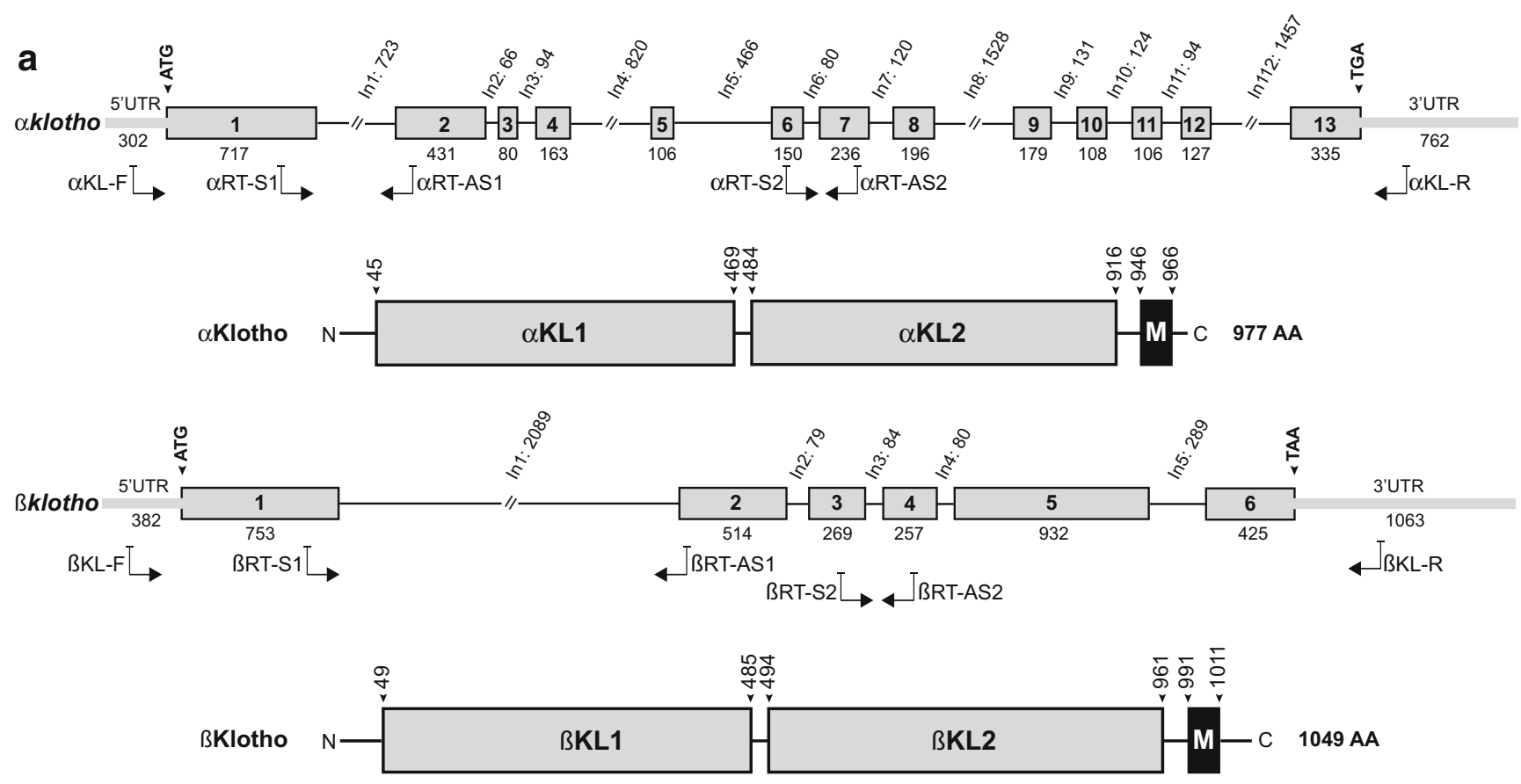

b

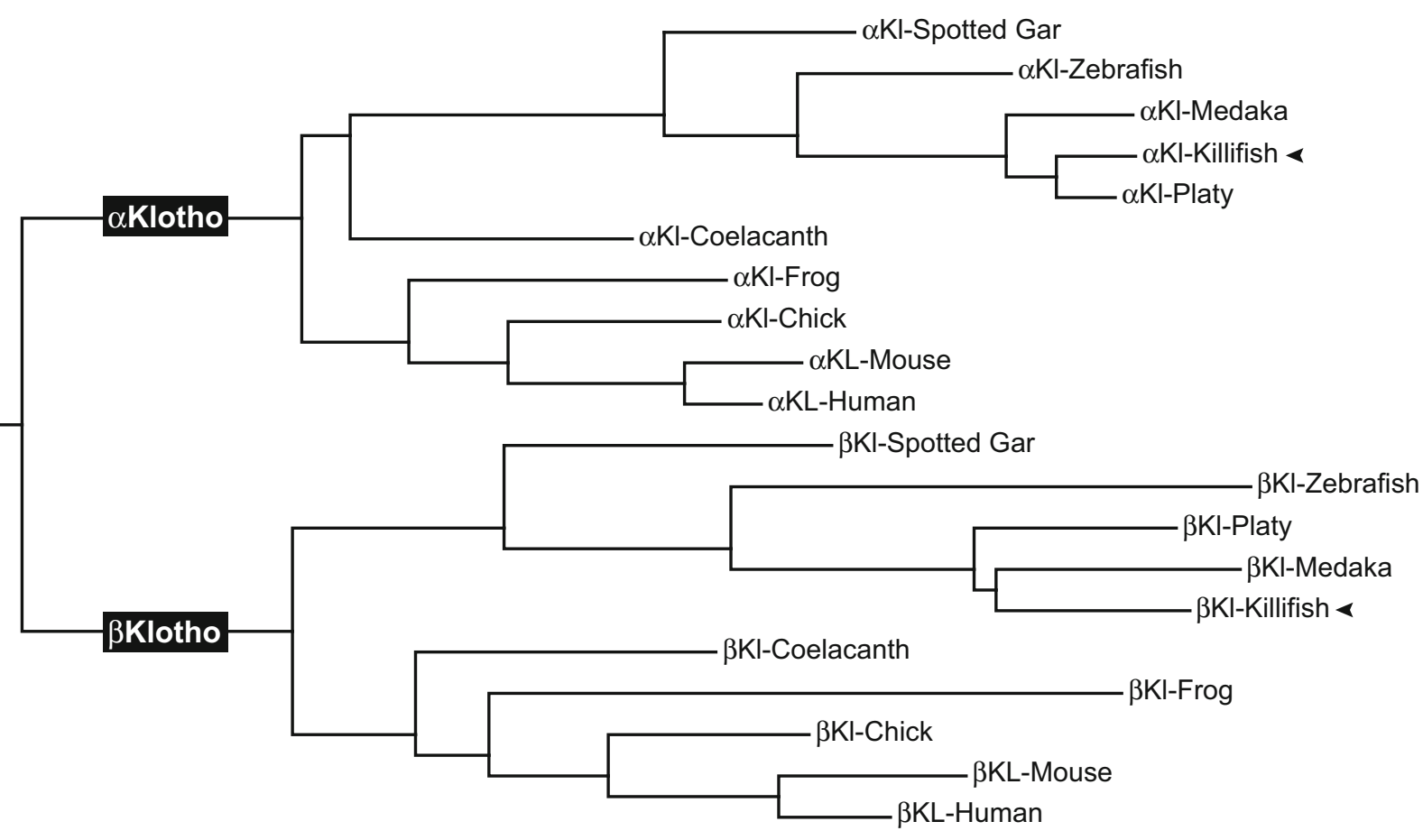

KI-Nematode

$\frac{0.1}{\text { stitutions per site }}$

(C. elegans) 
(ThermoFisher) and constructs representing $\alpha$ and $\beta k$ lotho were subject to Sanger sequencing (Microsynth). Sequence analysis was performed using Geneious software.

\section{Sequence comparison and phylogenetic analysis}

Protein sequences for alpha and beta Klotho family members were retrieved from the Ensembl genome database (Release 91; http://www.ensembl.org). We included the following species: human (Homo sapiens), mouse (Mus musculus), chicken (Gallus gallus), frog (Xenopus tropicalis), zebrafish (Danio rerio), spotted gar (Lepisosteus oculatus), medaka (Oryzias latipes), platyfish (Xiphophorus maculatus), and coelacanth (Latimeria chalumnae).

Killifish (Nothobranchius furzeri) sequences were obtained from the NFINgb genome browser (http://nfingb.leibniz-fli.de) (Reichwald et al. 2015). To artificially root the phylogenetic tree, we incorporated a Klotho homolog (C50F7.10) from the nematode Caenorhabditis elegans, which served as an outgroup. First, in order to obtain a high-quality multiple alignment, the sequences were compared using the muscle program (Edgar 2004). The phylogenetic tree was generated using the Maximum-Likelihood algorithm from the PhyML program (Guindon et al. 2009), applying the LG substitution matrix. The accession numbers of the sequences from which the protein sequences were retrieved are listed in supplementary Table 1.

\section{RNA isolation and quantitative real-time RT-PCR analysis}

Total RNA was isolated from whole fish and the brain, liver, and muscle samples with TRI reagent (Sigma-Aldrich) as recommended by the manufacturer. One microgram of total RNA was reverse transcribed with the iScript cDNA synthesis kit (Bio-Rad) and real-time RT-PCRs were performed using KAPA SYBR Fast Universal Master Mix (Kapa Biosystems) on a Bio-Rad CXF384 qPCR machine. Primer sequences for cloning and qRT-PCR analysis can be found in supplementary Table 2 .

\section{Immunohistochemistry}

IHC analysis was performed as previously described (Murko et al. 2013). In brief, samples were fixed with 4\% PFA, dehydrated, and embedded in paraffin by a routine embedding procedure. Four to five-micrometer sections were deparaffinized and rehydrated. Peroxidase activity was blocked using $1 \% \mathrm{H}_{2} \mathrm{O}_{2}$ in 1 xPBS for $15 \mathrm{~min}$ at room temperature. Samples, pretreated with heat-induced epitope retrieval (HIER) by steaming with citrate buffer for $30 \mathrm{~min}$, were permeabilized with $0.5 \%$ Triton $\mathrm{X}-100$ for $5 \mathrm{~min}$ at room temperature. After blocking, sections were incubated with a rabbit polyclonal anti-KL (Klotho) antibody (Sigma-Aldrich SAB2104815, immunogen:
HRGYSIRRGLFYVDFLSQDKMLLPKSSALFYQKLIEKNGFPPLPENQPLE corresponding to amino acids $433-482$ in the killifish $\alpha$ Klotho protein) diluted 1:200 overnight at $4{ }^{\circ} \mathrm{C}$ and then with a HRP-secondary antibody (Abcam) diluted 1:750 for $30 \mathrm{~min}$ at room temperature. Fluorescence signals were detected using the TSA Plus Fluorescence Kit (PerkinElmer) and counterstained with DAPI.

\section{In situ hybridization}

Transcription templates for in situ hybridization probes were generated by PCR amplification with primers including T7 and $\mathrm{T} 3$ transcription initiation sites to synthesize antisense and sense (control) probes, respectively. Digoxigenin-labeled riboprobes were in vitro transcribed using the T7-T3 MaxiScript System (Ambion). Primer sequences can be found in the "Electronic supplementary material" section. In situ hybridization was performed as previously described (Murko et al. 2010). Briefly, samples were fixed with $4 \%$ PFA, dehydrated, and embedded in paraffin by a routine embedding procedure. Four to five-micrometer sections were deparaffinized and rehydrated. Before hybridization, slides were post-fixed with $4 \% \mathrm{PFA}$, treated with $0.2-\mathrm{M} \mathrm{HCl}$ for $10 \mathrm{~min}$, followed by proteinase $\mathrm{K}$ digestion and dehydration. Air-dried sections were incubated with the probes, which were separately denatured at $92{ }^{\circ} \mathrm{C}$ for $5 \mathrm{~min}$, in the hybridization mix overnight in a humidified chamber at $55^{\circ} \mathrm{C}$. The hybridization mix contained $2 \mathrm{xSSC}, 50 \%$ formamide, $10 \%$ dextran sulfate, $0.02 \% \mathrm{SDS}$, with or without $100 \mathrm{ng} / \mu \mathrm{l}$ salmon sperm DNA, and $100 \mathrm{ng} / \mu \mathrm{l}$ yeast t-RNA. After stringency washes in $2 \mathrm{xSSC}$ at $42{ }^{\circ} \mathrm{C}$ or at $60{ }^{\circ} \mathrm{C}$ for $10 \mathrm{~min}$ three times and in $2 \mathrm{xSSC}$ at room temperature for $10 \mathrm{~min}$, blocking was done with $2 \%$ FCS for $30 \mathrm{~min}$. Probes were detected with an alkaline phosphatase conjugated anti-digoxigenin antibody (Roche) diluted 1:500 and signals were developed using NBT/BCIP (Roche).

\section{Statistical analysis}

Real-time PCR experiments were analyzed using CFX Maestro software and further graphically processed with Prism Graphpad software. The significance between groups was determined by the unpaired Student's $t$ test. $p$ values were calculated with the Prism software and standard deviation (s.d.) is shown. $* p<0.05 ; * * p<0.01 ; * * * p<0.001$.

\section{Results and discussion}

\section{Evolutionary relationships of the Klotho family}

To identify Klotho family genes in killifish, we screened the recently annotated genome of $N$. furzeri (Reichwald et al. 
Table 1 Pairwise sequence comparison between killifish and human Klotho gene family members. The percentage similarity was scored using Geneious software

\begin{tabular}{lllll}
\hline & $\begin{array}{l}\alpha \text { KL- } \\
\text { Human }\end{array}$ & $\begin{array}{l}\alpha \text { Kl- } \\
\text { Killifish }\end{array}$ & $\begin{array}{l}\beta \text { KL- } \\
\text { Human }\end{array}$ & $\begin{array}{l}\beta \text { Kl- } \\
\text { Killifish }\end{array}$ \\
\hline$\alpha$ KL-Human & & $64.14 \%$ & $57.84 \%$ & $54.51 \%$ \\
$\alpha$ Kl-Killifish & $64.14 \%$ & & $55.81 \%$ & $53.72 \%$ \\
$\beta$ KL-Human & $57.84 \%$ & $55.81 \%$ & & $61.40 \%$ \\
$\beta$ Kl-Killifish & $54.51 \%$ & $53.72 \%$ & $61.40 \%$ & \\
\hline
\end{tabular}

Italics is used to emphasize the percentage similarity of orthologs comparing killifish with human

2015; Valenzano et al. 2015). Data mining of the publicly available databases (http://nfingb.leibniz-fli.de) produced two genes with significant homology to human and mouse orthologs of $\alpha k l o t h o$ (Nfu_g_1_022108) and $\beta k l o t h o$ (Nfu_g_1_004524).

Killifish $\alpha$ klotho and $\beta$ klotho are predicted to consist of 13 and 6 exons accounting for an open reading frame of $2934 \mathrm{bp}$ (977 amino acids) and $3150 \mathrm{bp}$ (1049 amino acids), respectively. To clone full-length killifish klotho orthologs, reverse transcription-polymerase (RT-PCR) was performed on cDNA from 5-week-old whole fish using gene-specific primer (Fig. 1a). Pairwise sequence comparison between killifish and human full-length Klotho proteins demonstrates a high degree of conservation, sharing $64 \%$ and $61 \%$ sequence similarity for $\alpha$ Klotho and $\beta$ Klotho, respectively. Moreover, sequence similarities of the individual Klotho proteins between species are higher than homologies within the same species (Table 1). The protein alignment also revealed that the killifish Klotho orthologs encode the same type 1 transmembrane protein as its human counterpart, with two internal repeats KL1 and KL2 in the extracellular domain (Fig. 1a). In mammals, Nterminal signal sequences have been described for both Klotho paralogs (Kuro-o et al. 1997; Ito et al. 2000) which is apparently lacking in zebrafish $\alpha$ Klotho (Sugano and Lardelli 2011) and also in the two Klotho paralogs in the nematode Caenorhabditis elegans (Château et al. 2010). Using the protein prediction resource InterProScan (Finn et al. 2017), we found a strong putative signal sequence for both killifish orthologs $\alpha$ Klotho (AA 1-18) and $\beta$ Klotho (AA 1-25). Notably, although killifish and zebrafish $\alpha$ Klotho share more than $80 \%$ sequence similarity, the N-terminal part does not show a significant degree of conservation (Supplementary Fig. 1). To examine the evolutionary relationships of killifish Klotho proteins within the vertebrate genomes, we performed phylogenetic analysis on amino acid sequences of Klotho homologs of human, mouse, chicken, xenopus, coelacanth, spotted gar, zebrafish, medaka, platy, and killifish. Coelacanth was included because of its status as a living fossil, representing sarcopterygian fish which transitioned to a terrestrial life, giving rise to modern tetrapods (Amemiya et al. 2013). The spotted gar, which diverged before the teleost-specific genome duplication, represents the unduplicated sister group of teleosts (Braasch et al. 2016). A phylogenetic tree employing the Maximum-Likelihood algorithm demonstrates that the different Klotho paralogs grouped explicitly within their distinct clade, displaying highest conservation with other teleost species.

\section{Strong induction of aklotho and $\beta$ klotho expression post hatching}

To gain insight into the temporal expression profiles of Klotho family members, we compared three different time points during the early killifish life cycle by quantitative real-time PCR (qRT-PCR): embryonic day 14 (E14), shortly after hatching (D01), and week 5 (W05). Transcripts of both orthologs, $\alpha k l o t h o$ and $\beta k l o t h o$, were detected during embryogenesis. After hatching, a slight increase in mRNA expression was observed, followed by further strong induction in transcript

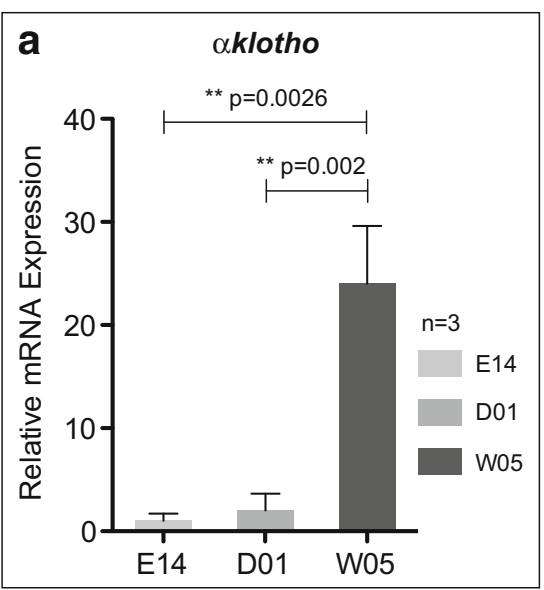

Fig. 2 Expression of both $\mathbf{a} \alpha$ klotho and $\mathbf{b} \beta$ klotho is strongly induced in adult fish. Relative expression was evaluated by qRT-PCR of klotho family members in $N$. furzeri whole fish cDNA extracts at embryonic day 14 (E14) corresponding to the "black eye" stage, post hatching day 1 (D01),

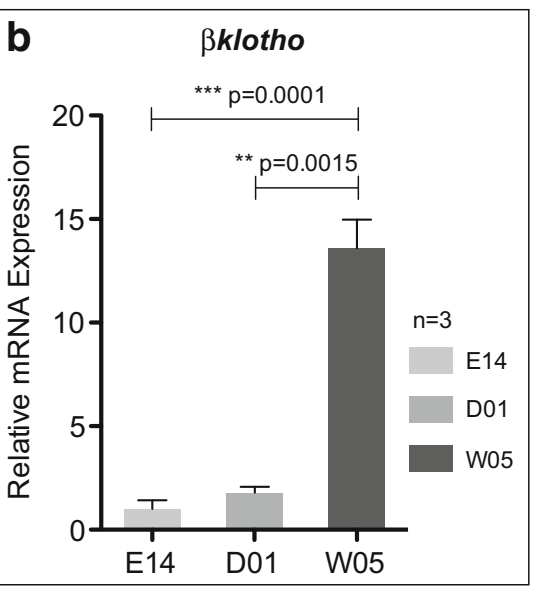

and 5 weeks of age (W05) in triplicate. Gene expression was normalized to TATA-binding protein (TBP). All E14 data points are set to 1. Error bars represent $\pm \mathrm{SD}$. Student's unpaired $t$ test: ns $p>0.05 ; * p<0.05$; $* * p<0.01 ; * * * p<0.001$ 


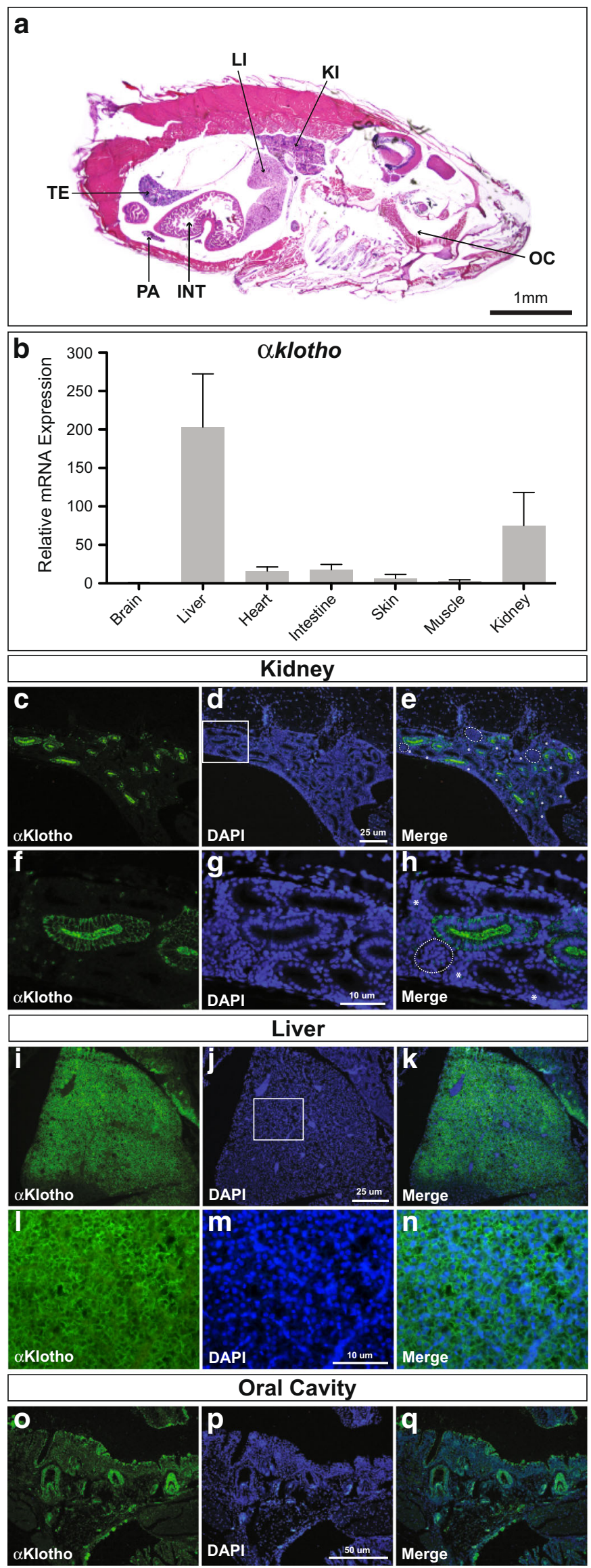


Fig. 3 High expression levels of $\alpha$ klotho in the killifish liver and kidney. a Hematoxylin and Eosin staining of a sagittal section of 5-week-old fish. $I N T$ intestines, $L I$ liver, $K I$ kidney, $O C$ oral cavity, $P A$ pancreas, $T E$ testis. b Relative expression of $\alpha$ klotho in multiple tissues was determined by qRT-PCR at time point 5 weeks of three biological replicates. Expression of $\alpha$ klotho was normalized to TATA-binding protein (TBP) gene expression. Fluorescence immunohistochemistry with an anti- $\alpha$ Klotho antibody showing $\alpha$ Klotho protein expression in the $\mathbf{c}-\mathbf{h}$ kidney, $\mathbf{i}-\mathbf{n}$ liver, and $\mathbf{o}-\mathbf{q}$ oral cavity. Nuclei are counterstained with DAPI and merged with signals obtained from $\alpha$ Klotho-specific stainings. White boxes indicate regions shown in higher magnifications; dotted white lines encircle glomeruli; hematopoietic cells are marked with an asterisk

levels within the first weeks of adult development (Fig. 2). These results agree with previous findings in zebrafish showing that $\alpha$ klotho transcripts were evident during early embryonic stages and gradually increased as development proceeded (Sugano and Lardelli 2011). Also in mouse, $\alpha$ Klotho immunoreactivity was initially observed at embryonic day 16 followed by an apparent induction after birth (Song et al. 2014). A similar temporal expression profile has been
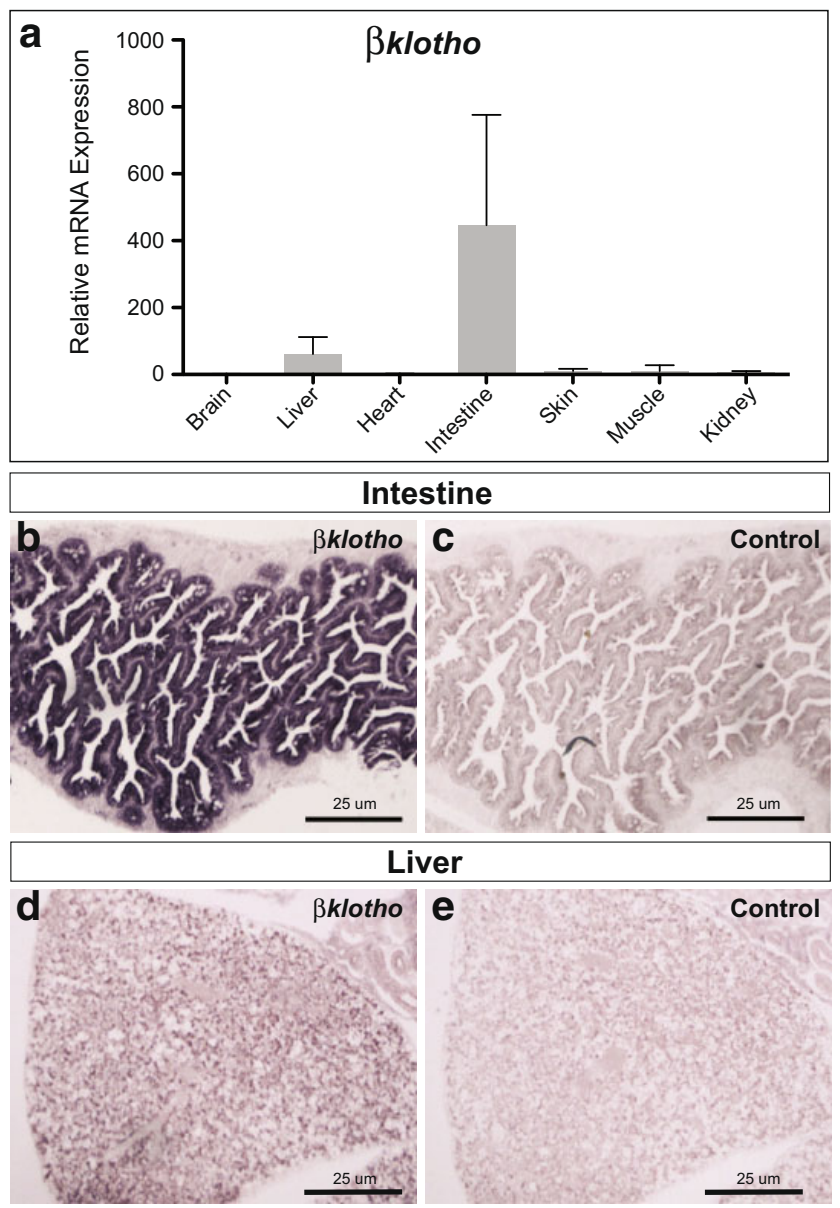

Fig. 4 Expression of $\beta k$ lotho in the killifish intestine and liver. a Relative expression of $\beta$ klotho in multiple tissues was determined by qRT-PCR at time point 5 weeks of three biological replicates. Expression of $\beta k l o t h o$ was normalized to TATA-binding protein (TBP) gene expression. Detection of $\beta$ klotho mRNAs by in situ hybridization (ISH) in $\mathbf{b}$ intestine and $\mathbf{d}$ liver. c, e sense probes were used as controls reported for murine $\beta k l o t h o$, with transcription being progressively induced post-embryonic development (Ito et al. 2000). The fact that Klotho family members show only low levels of expression during embryogenesis in different vertebrate species suggests that $\alpha$ Klotho and $\beta$ Klotho might not play an important role during embryonic development.

\section{Prominent expression of aklotho in the adult killifish liver and kidney}

In mammals, the $\alpha$ klotho gene is expressed predominantly in the distal convoluted tubules of the kidney, the chief cells of the parathyroid gland, and the choroid plexus (Kuro-o et al. 1997) but has also been detected in additional tissues that were not included in the initial screens, such as reproductive organs ( $\mathrm{Li}$ et al. 2004), the inner ear (Kamemori et al. 2002), the eye (Zhang et al. 2017), breast tissue (Wolf et al. 2008), bone cells (Kaludjerovic et al. 2017), and monocytes (Bacchetta et al. 2013). Also, a recent study combining immunohistochemistry with mass spectrometry reports widespread expression of transmembrane $\alpha$ Klotho in various human tissues (Lim et al. 2015). To characterize tissue expression of $\alpha$ klotho in killifish, qRT-PCR was performed on different tissues of 5-week-old fish (Fig. 5a). We detected $\alpha$ klotho expression in several adult tissues, being most prominent in the liver and kidney (Fig. 3b). To validate the significance of qRTPCR data on the protein level, we performed immunostaining using an anti- $\alpha$ Klotho antibody on adult killifish tissues. Faint signal was detected in several tissues including the brain, testis, pancreas, and intestine while strong expression was observed in the kidney, liver, and pharyngeal teeth. A similar expression pattern has been reported in developing zebrafish (Mangos et al. 2012). Moreover, $\alpha$ klotho expression in $N$. furzeri is in line with the mammalian expression pattern. Particularly, high levels of protein were consistently identified in rat and mouse kidney tubules, whereas gene expression revealed weak signals in other organs including the brain (Kuro-o et al. 1997; Li et al. 2004). The morphology of the $N$. furzeri kidney has recently been described (Hoppe et al. 2015). Immunofluorescence distinctly highlighted tubules of nephrons, while no signal was found in glomeruli and hematopoietic cells (Fig. 3c-e). Subcellular signal predominately localized to cell membranes with the apical portion displaying the strongest signal (Fig. $3 \mathrm{f}-\mathrm{h}$ ). The lateral cell membranes were less strongly labeled but signal intensity increased towards the membranes of the baso-lateral compartment of tubular cells. Interestingly, the basal compartment appeared almost devoid of signal. Together, these findings corroborate results obtained from the mammalian kidney where $\alpha$ Klotho is expressed in specific sections of the tubules, namely predominantly in 
Fig. 5 Relative gene expression profile of klotho family members during the aging process. a Agedependent mortality of $N$. furzeri strain GRZ. Kaplan Meier estimates of survival for male $(n=$ $56)$ and female $(n=57)$ populations. Total number of fish $n=$ 113. Selected time points for RTqPCR analysis are indicated. Temporal gene expression of $\alpha$ klotho in b liver and c kidney, and of $\beta$ lotho in $\mathbf{d}$ intestines, and e liver comparing young (W05), aged (W11), and old (W13) $N$. furzeri GRZ was evaluated by RT-qPCR. Gene expression was normalized to TATA-binding protein (TBP). All W05 data points are set to 1 . Error bars represent \pm SD of three biological replicates. Student's unpaired $t$ test: ns $p>0.05 ; * p<0.05$; $* * p<0.01 ; * * * p<0.001$
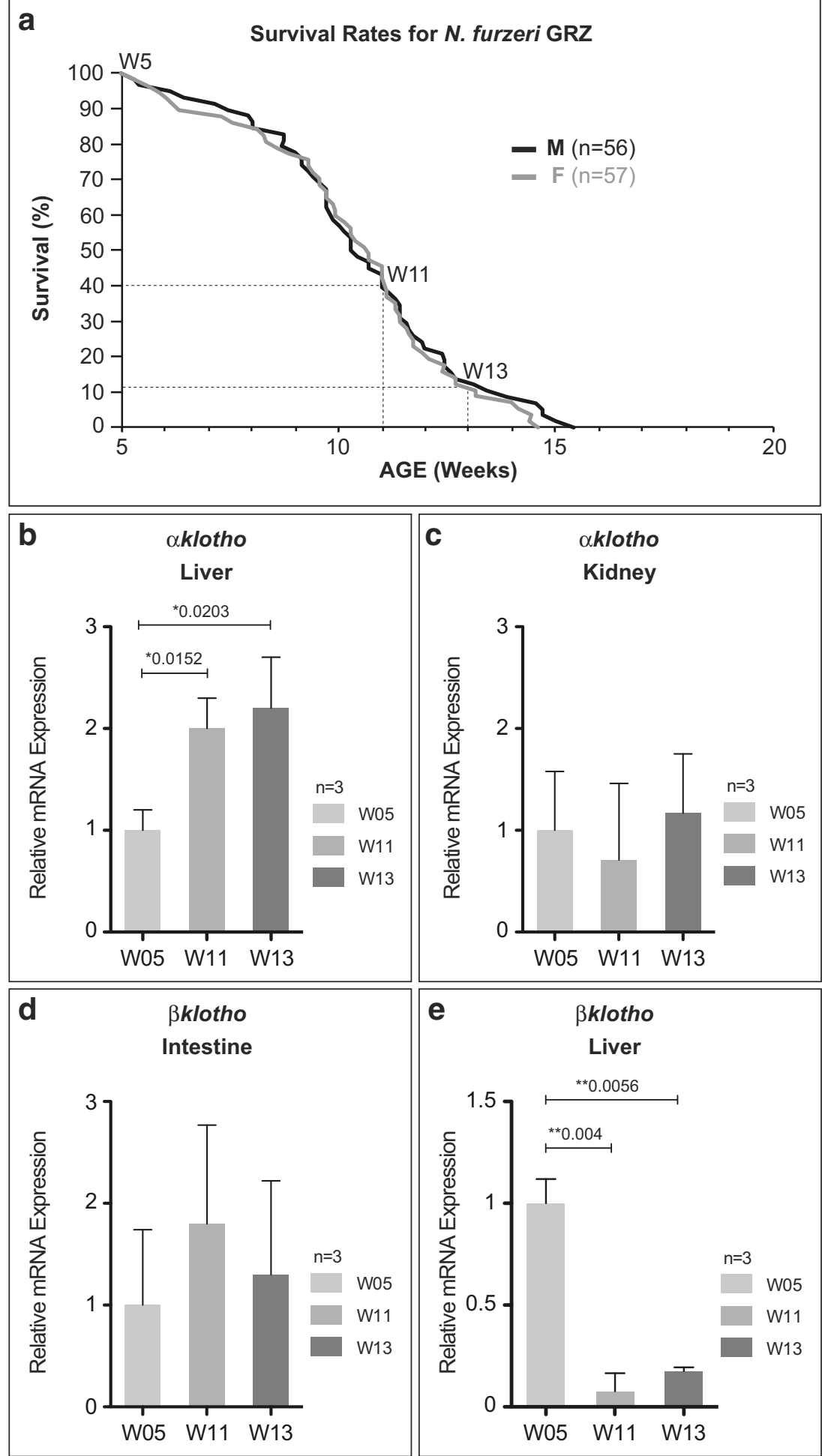

the distal convoluted tubules and not elsewhere in the kidney (Kuro-o et al. 1997; Song et al. 2014). Robust $\alpha$ Klotho protein expression was also observed in the liver of $N$. furzeri (Fig. 3i-k) with the signal predominately localized at hepatocyte cell membranes (Fig. 31-n), concurring with its physiological function as a transmembrane protein. Prominent hepatic expression of $\alpha$ klotho was also reported in the liver of the longer-lived MZM 0410 strain of $N$. furzeri (GEO Accession number: GSE66712) whereas in mammals, it is $\beta$ Klotho, which is primarily expressed in the liver tissue (Lim et al. 2015). Strong $\alpha$ Klotho expression was also detected in 
developing pharyngeal teeth of the oral cavity of $N$. furzeri (Fig. 3o-q). This expression site may be linked to mineralization of hard tissue considering the importance of $\alpha$ Klotho in electrolyte homeostasis. Indeed, mice lacking functional Klotho gene display tooth malformations (Hikone et al. 2017).

\section{Expression of $\beta k$ lotho in the adult killifish intestine and liver}

Although $\alpha$ Klotho and $\beta$ Klotho share high sequence homology and structural similarity, their reported tissue-specific expression patterns differ considerably, with $\beta k l o t h o$ being predominantly expressed in the liver, pancreas, and adipose tissue of adult mice (Ito et al. 2000).

To investigate killifish $\beta k$ lotho expression in the spatial context, different tissues of 5-week-old fish were analyzed by qRT-PCR. $\beta k$ lotho transcripts were detected in the intestine and liver, with expression being particularly prominent in the intestinal tissue (Fig. 4a). In order to correlate qPCR data with morphology, we performed RNA in situ hybridization. Most prominent expression levels were identified in the intestine, where the signal was confined to the epithelial layer (Fig. 4b, c), and in the liver (Fig. 4d, e). Weaker expression was found in the kidney, pancreas, skeletal muscle, and testis (not shown). In general, the observed expression pattern closely resembles that in mice (Ito et al. 2000).

\section{Expression of Klotho family members during the aging process}

Although numerous reports have addressed expression of Klotho members in different tissues and in the context of varying Klotho levels, there is limited information on temporal expression profiles during the aging process. A study in humans, comparing serum levels of secreted $\alpha$ Klotho between children and adults, demonstrated that the circulating form of $\alpha$ Klotho correlates negatively with age (Yamazaki et al. 2010). This decrease in $\alpha$ Klotho levels over time has also been observed in cerebrospinal fluid of humans. Additionally, the same study reports lower $\alpha$ Klotho levels in older adults with Alzheimer's disease (Semba et al. 2014). Furthermore, it has been shown that both $\alpha$ klotho mRNA and protein expression are downregulated in brains of monkeys, rats, and mice with age. Of note, this age-dependent downregulation of $\alpha$ Klotho was only detected in white matter, as gray matter showed no significant differences in expression with age, suggesting cell type-specific regulation even within the same tissue (Duce et al. 2008). To characterize individual Klotho family members as a function of age, we performed qRT-PCR analyses of tissues showing prominent $\alpha$ klotho and $\beta k$ lotho expression (Figs. 3b and 4a). We compared three different time points, covering the entire killifish lifespan: week 5
(W05), week 11 (W11), and week 13 (W13). At W05, $N$. furzeri has reached sexual maturity, representing a young adult. Age W11 corresponds to approximately $40 \%$ survivorship in our colony (Fig. 5a). With survival rates having declined to $10-15 \%$, W13 is defined as old age, indicated by a drastic decline in performance and display of typical agingrelated phenotypes. Concerning aklotho regulation, we observed a gradual increase in transcription in the liver, whereas in the kidney, mRNA levels stayed unchanged during the aging process (Fig. $5 \mathrm{~b}, \mathrm{c}$ ). These results are in accordance with a recent study characterizing age-related transcriptional changes comparing gene expression in kidneys of 14 and 96-week-old wild-type mice. Transcriptomic profiling revealed unchanged expression levels of $\alpha$ klotho during renal aging (Braun et al. 2016). In the case of $\beta k l o t h o$, we found transcript levels to be steady in the intestine, whereas in the liver, a significant downregulation with age was observed (Fig. 5d, e). A recent study has shown that expression of $\beta k$ lotho was downregulated in human hepatocellular carcinoma tissues whereas its overexpression could inhibit tumorigenesis, hinting towards a role of $\beta$ Klotho as a tumor suppressor in the liver (Ye et al. 2013). Histological analysis revealed high incidence of neoplastic lesions in the liver of $N$. furzeri with age (Di Cicco et al. 2011) suggesting a similar function of $\beta$ Klotho in killifish. Decreased expression of $\beta$ klotho in aged killifish liver might contribute to the observed phenotype.

Together, the high degree of conservation of the Klotho gene family in killifish and a tissue expression resembling mammals make $N$. furzeri an attractive experimental model system to further analyze pathways and molecular mechanisms that underlie the anti-aging properties of Klotho members. Work is ongoing to examine whether $\alpha$ Klotho overexpression reproduces lifespan expansion in this new model system.

Acknowledgements Open access funding provided by Austrian Science Fund (FWF). The authors would like to thank the Valenzano Lab, Max Plank Institute for Biology of Ageing, Cologne for kindly providing the GRZ strain and their continuous support. We are thankful to the Cellerino Lab, Pisa, for sharing their expertise and invaluable help in establishing a Nothobranchius colony in Vienna.

Author contributions G.Z. and O.P. designed all the experiments. G.Z. performed all the killifish experiments. D.M. performed all phylogenetic analyses. J.K. conducted the qRT-PCR experiments. S.L. assisted with in situ hybridization and IHC analyses. C. S provided intellectual contributions. O.P. designed the figures and wrote the manuscript with input from all authors.

Funding information This study was supported by the Austrian Science Fund (FWF) grant P30642 to C. Schöfer.

\section{Compliance with ethical standards}

All killifish experiments and procedures were performed according to the "Principles of laboratory animal care" as well as to ethical standards of the Ethics Committee of the Medical University of Vienna. 
Competing interests The authors declare that they have no competing interests.

Open Access This article is distributed under the terms of the Creative Commons Attribution 4.0 International License (http:// creativecommons.org/licenses/by/4.0/), which permits unrestricted use, distribution, and reproduction in any medium, provided you give appropriate credit to the original author(s) and the source, provide a link to the Creative Commons license, and indicate if changes were made.

\section{References}

Amemiya CT, Alföldi J, Lee AP, Fan S, Philippe H, MacCallum I, Braasch I, Manousaki T, Schneider I, Rohner N, Organ C, Chalopin D, Smith JJ, Robinson M, Dorrington RA, Gerdol M, Aken B, Biscotti MA, Barucca M, Baurain D, Berlin AM, Blatch GL, Buonocore F, Burmester T, Campbell MS, Canapa A, Cannon JP, Christoffels A, de Moro G, Edkins AL, Fan L, Fausto AM, Feiner N, Forconi M, Gamieldien J, Gnerre S, Gnirke A, Goldstone JV, Haerty W, Hahn ME, Hesse U, Hoffmann S, Johnson J, Karchner SI, Kuraku S, Lara M, Levin JZ, Litman GW, Mauceli E, Miyake T, Mueller MG, Nelson DR, Nitsche A, Olmo E, Ota T, Pallavicini A, Panji S, Picone B, Ponting CP, Prohaska SJ, Przybylski D, Saha NR, Ravi V, Ribeiro FJ, Sauka-Spengler T, Scapigliati G, Searle SMJ, Sharpe T, Simakov O, Stadler PF, Stegeman JJ, Sumiyama K, Tabbaa D, Tafer H, Turner-Maier J, van Heusden $\mathrm{P}$, White S, Williams L, Yandell M, Brinkmann $\mathrm{H}$, Volff JN, Tabin CJ, Shubin N, Schartl M, Jaffe DB, Postlethwait JH, Venkatesh B, di Palma F, Lander ES, Meyer A, Lindblad-Toh K (2013) The African coelacanth genome provides insights into tetrapod evolution. Nature 496:311-316. https://doi.org/10.1038/ nature 12027

Bacchetta J, Sea JL, Chun RF, Lisse TS, Wesseling-Perry K, Gales B, Adams JS, Salusky IB, Hewison M (2013) Fibroblast growth factor 23 inhibits extrarenal synthesis of 1,25-dihydroxyvitamin D in human monocytes. J Bone Miner Res 28:46-55. https://doi.org/10. 1002/jbmr. 1740

Braasch I, Gehrke AR, Smith JJ, Kawasaki K, Manousaki T, Pasquier J, Amores A, Desvignes T, Batzel P, Catchen J, Berlin AM, Campbell MS, Barrell D, Martin KJ, Mulley JF, Ravi V, Lee AP, Nakamura T, Chalopin D, Fan S, Wcisel D, Cañestro C, Sydes J, Beaudry FEG, Sun Y, Hertel J, Beam MJ, Fasold M, Ishiyama M, Johnson J, Kehr S, Lara M, Letaw JH, Litman GW, Litman RT, Mikami M, Ota T, Saha NR, Williams L, Stadler PF, Wang H, Taylor JS, Fontenot Q, Ferrara A, Searle SMJ, Aken B, Yandell M, Schneider I, Yoder JA, Volff JN, Meyer A, Amemiya CT, Venkatesh B, Holland PWH, Guiguen Y, Bobe J, Shubin NH, di Palma F, Alföldi J, LindbladToh K, Postlethwait JH (2016) The spotted gar genome illuminates vertebrate evolution and facilitates human-teleost comparisons. Nat Genet 48:427-437. https://doi.org/10.1038/ng.3526

Braun F, Rinschen MM, Bartels V, Frommolt P, Habermann B, Hoeijmakers JHJ, Schumacher B, Dollé MET, Müller RU, Benzing T, Schermer B, Kurschat CE (2016) Altered lipid metabolism in the aging kidney identified by three layered omic analysis. Aging (Albany NY) 8:441-457. https://doi.org/10.18632/aging.100900

Château M-T, Araiz C, Descamps S, Galas S (2010) Klotho interferes with a novel FGF-signalling pathway and insulin/Igf-like signalling to improve longevity and stress resistance in Caenorhabditis elegans. Aging (Albany NY) 2:567-581. https://doi.org/10.18632/ aging. 100195

Di Cicco E, Tozzini ET, Rossi G, Cellerino A (2011) The short-lived annual fish Nothobranchius furzeri shows a typical teleost aging process reinforced by high incidence of age-dependent neoplasias. Exp Gerontol 46:249-256. https://doi.org/10.1016/j.exger.2010.10.011
Duce JA, Podvin S, Hollander W, Kipling D, Rosene DL, Abraham CR (2008) Gene profile analysis implicates Klotho as an important contributor to aging changes in brain white matter of the rhesus monkey. Glia 56:106-117. https://doi.org/10.1002/glia.20593

Edgar RC (2004) MUSCLE: multiple sequence alignment with high accuracy and high throughput. Nucleic Acids Res 32:1792-1797. https://doi.org/10.1093/nar/gkh340

Finn RD, Attwood TK, Babbitt PC, Bateman A, Bork P, Bridge AJ, Chang HY, Dosztányi Z, el-Gebali S, Fraser M, Gough J, Haft D, Holliday GL, Huang H, Huang X, Letunic I, Lopez R, Lu S, Marchler-Bauer A, Mi H, Mistry J, Natale DA, Necci M, Nuka G, Orengo CA, Park Y, Pesseat S, Piovesan D, Potter SC, Rawlings ND, Redaschi N, Richardson L, Rivoire C, Sangrador-Vegas A, Sigrist C, Sillitoe I, Smithers B, Squizzato S, Sutton G, Thanki N, Thomas PD, Tosatto SCE, Wu CH, Xenarios I, Yeh LS, Young SY, Mitchell AL (2017) InterPro in 2017-beyond protein family and domain annotations. Nucleic Acids Res 45:D190-D199. https:// doi.org/10.1093/nar/gkw1107

Guindon S, Delsuc F, Dufayard J-F, Gascuel O (2009) Estimating maximum likelihood phylogenies with PhyML. Methods in molecular biology (Clifton, NJ):113-137

Harel I, Benayoun BA, Machado B, Singh PP, Hu CK, Pech MF, Valenzano DR, Zhang E, Sharp SC, Artandi SE, Brunet A (2015) A platform for rapid exploration of aging and diseases in a naturally short-lived vertebrate. Cell 160:1013-1026. https://doi.org/10.1016/ j.cell.2015.01.038

Hikone K, Hasegawa T, Tsuchiya E, Hongo H, Sasaki M, Yamamoto T, Kudo A, Oda K, Haraguchi M, de Freitas PHL, Li M, Iida J, Amizuka N (2017) Histochemical examination on periodontal tissues of Klotho-deficient mice fed with phosphate-insufficient diet. J Histochem Cytochem 65:207-221. https://doi.org/10.1369/ 0022155416689670

Hoppe B, Pietsch S, Franke M, Engel S, Groth M, Platzer M, Englert C (2015) MiR-21 is required for efficient kidney regeneration in fish. BMC Dev Biol 15:43. https://doi.org/10.1186/s12861-015-0089-2

Imura A, Iwano A, Tohyama O, Tsuji Y, Nozaki K, Hashimoto N, Fujimori T, Nabeshima YI (2004) Secreted Klotho protein in sera and CSF: implication for post-translational cleavage in release of Klotho protein from cell membrane. FEBS Lett 565:143-147. https://doi.org/10.1016/j.febslet.2004.03.090

Ito S, Kinoshita S, Shiraishi N, Nakagawa S, Sekine S, Fujimori T, Nabeshima YI (2000) Molecular cloning and expression analyses of mouse betaklotho, which encodes a novel Klotho family protein. Mech Dev 98:115-119

Kaludjerovic J, Komaba H, Sato T, Erben RG, Baron R, Olauson H, Larsson TE, Lanske B (2017) Klotho expression in long bones regulates FGF23 production during renal failure. FASEB J 31:20502064. https://doi.org/10.1096/fj.201601036R

Kamemori M, Ohyama Y, Kurabayashi M, Takahashi K, Nagai R, Furuya N (2002) Expression of Klotho protein in the inner ear. Hear Res $171: 103-110$

Kuro-o M, Matsumura Y, Aizawa H, Kawaguchi H, Suga T, Utsugi T, Ohyama Y, Kurabayashi M, Kaname T, Kume E, Iwasaki H, Iida A, Shiraki-Iida T, Nishikawa S, Nagai R, Nabeshima YI (1997) Mutation of the mouse klotho gene leads to a syndrome resembling ageing. Nature 390:45-51. https://doi.org/10.1038/36285

Kurosu H, Yamamoto M, Clark JD, Pastor JV, Nandi A, Gurnani P, McGuinness O, Chikuda H, Yamaguchi M, Kawaguchi H, Shimomura I, Takayama Y, Herz J, Kahn CR, Rosenblatt KP, Kuro-o M (2005) Suppression of aging in mice by the hormone Klotho. Science 309:1829-1833. https://doi.org/10.1126/science. 1112766

Li S-A, Watanabe M, Yamada H, Nagai A, Kinuta M, Takei K (2004) Immunohistochemical localization of Klotho protein in brain, kidney, and reproductive organs of mice. Cell Struct Funct 29:91-99 
Lim K, Groen A, Molostvov G, Lu T, Lilley KS, Snead D, James S, Wilkinson IB, Ting S, Hsiao LL, Hiemstra TF, Zehnder D (2015) $\alpha$-Klotho expression in human tissues. J Clin Endocrinol Metab 100:E1308-E1318. https://doi.org/10.1210/jc.2015-1800

Mangos S, Amaral AP, Faul C, Juppner H, Reiser J, Wolf M (2012) Expression of fgf 23 and $\alpha$ klotho in developing embryonic tissues and adult kidney of the zebrafish, Danio rerio. Nephrol Dial Transplant 27:4314-4322. https://doi.org/10.1093/ndt/gfs335

Murko C, Lagger S, Steiner M, Seiser C, Schoefer C, Pusch O (2013) Histone deacetylase inhibitor Trichostatin A induces neural tube defects and promotes neural crest specification in the chicken neural tube. Differentiation 85:55-66. https://doi.org/10.1016/j.diff.2012. 12.001

Murko C, Lagger S, Steiner M, Seiser C, Schoefer C, Pusch O (2010) Expression of class I histone deacetylases during chick and mouse development. Int J Dev Biol 54:1525-1535. https://doi.org/10.1387/ ijdb.092971 cm

Ogawa Y, Kurosu H, Yamamoto M, Nandi A, Rosenblatt KP, Goetz R, Eliseenkova AV, Mohammadi M, Kuro-o M (2007) betaKlotho is required for metabolic activity of fibroblast growth factor 21 . Proc Natl Acad Sci 104:7432-7437. https://doi.org/10.1073/pnas. 0701600104

Reichwald K, Petzold A, Koch P, Downie BR, Hartmann N, Pietsch S, Baumgart M, Chalopin D, Felder M, Bens M, Sahm A, Szafranski K, Taudien S, Groth M, Arisi I, Weise A, Bhatt SS, Sharma V, Kraus JM, Schmid F, Priebe S, Liehr T, Görlach M, Than ME, Hiller M, Kestler HA, Volff JN, Schartl M, Cellerino A, Englert C, Platzer M (2015) Insights into sex chromosome evolution and aging from the genome of a short-lived fish. Cell 163:1527-1538. https://doi.org/ 10.1016/j.cell.2015.10.071

Semba RD, Moghekar AR, Hu J, Sun K, Turner R, Ferrucci L, O’Brien R (2014) Klotho in the cerebrospinal fluid of adults with and without Alzheimer's disease. Neurosci Lett 558:37-40. https://doi.org/10. 1016/j.neulet.2013.10.058

Song JH, Lee MY, Kim YJ, Park SR, Kim J, Ryu SY, Jung JY (2014) Developmental immunolocalization of the Klotho protein in mouse kidney epithelial cells. Eur J Histochem 58:2256. https://doi.org/10. 4081/ejh.2014.2256

Sugano Y, Lardelli M (2011) Identification and expression analysis of the zebrafish orthologue of Klotho. Dev Genes Evol 221:179-186. https://doi.org/10.1007/s00427-011-0367-3

Terzibasi E, Lefrançois C, Domenici P, Hartmann N, Graf M, Cellerino A (2009) Effects of dietary restriction on mortality and age-related phenotypes in the short-lived fish Nothobranchius furzeri. Aging Cell 8:88-99. https://doi.org/10.1111/j.1474-9726.2009.00455.x
Urakawa I, Yamazaki Y, Shimada T, Iijima K, Hasegawa H, Okawa K, Fujita T, Fukumoto S, Yamashita T (2006) Klotho converts canonical FGF receptor into a specific receptor for FGF23. Nature 444: 770-774. https://doi.org/10.1038/nature05315

Valdesalici S, Cellerino A (2003) Extremely short lifespan in the annual fish Nothobranchius furzeri. Proc R Soc B Biol Sci 270(Suppl):189 191. https://doi.org/10.1098/rsbl.2003.0048

Valenzano DR, Benayoun BA, Singh PP, Zhang E, Etter PD, Hu CK, Clément-Ziza M, Willemsen D, Cui R, Harel I, Machado BE, Yee MC, Sharp SC, Bustamante CD, Beyer A, Johnson EA, Brunet A (2015) The African turquoise killifish genome provides insights into evolution and genetic architecture of lifespan. Cell 163:1539-1554. https://doi.org/10.1016/j.cell.2015.11.008

Valenzano DR, Terzibasi E, Cattaneo A, Domenici L, Cellerino A (2006a) Temperature affects longevity and age-related locomotor and cognitive decay in the short-lived fish Nothobranchius furzeri. Aging Cell 5:275-278. https://doi.org/10.1111/j.1474-9726.2006. 00212.x

Valenzano DR, Terzibasi E, Genade T, Cattaneo A, Domenici L, Cellerino A (2006b) Resveratrol prolongs lifespan and retards the onset of age-related markers in a short-lived vertebrate. Curr Biol 16:296-300. https://doi.org/10.1016/j.cub.2005.12.038

Wolf I, Levanon-Cohen S, Bose S, Ligumsky H, Sredni B, Kanety H, Kuro-o M, Karlan B, Kaufman B, Koeffler HP, Rubinek T (2008) Klotho: a tumor suppressor and a modulator of the IGF-1 and FGF pathways in human breast cancer. Oncogene 27:7094-7105. https:// doi.org/10.1038/onc.2008.292

Yamazaki Y, Imura A, Urakawa I, Shimada T, Murakami J, Aono Y, Hasegawa H, Yamashita T, Nakatani K, Saito Y, Okamoto N, Kurumatani N, Namba N, Kitaoka T, Ozono K, Sakai T, Hataya H, Ichikawa S, Imel EA, Econs MJ, Nabeshima YI (2010) Establishment of sandwich ELISA for soluble alpha-Klotho measurement: age-dependent change of soluble alpha-Klotho levels in healthy subjects. Biochem Biophys Res Commun 398:513-518. https://doi.org/10.1016/j.bbrc.2010.06.110

Ye X, Guo Y, Zhang Q, Chen W, Hua X, Liu W, Yang Y, Chen G (2013) $\beta$ Klotho suppresses tumor growth in hepatocellular carcinoma by regulating Akt/GSK-3 $\beta /$ cyclin D1 signaling pathway. PLoS One 8: e55615. https://doi.org/10.1371/journal.pone.0055615

Zhang Y, Wang L, Wu Z, Yu X, du X, Li X (2017) The expressions of Klotho family genes in human ocular tissues and in anterior Lens capsules of age-related cataract. Curr Eye Res 42:871-875. https:// doi.org/10.1080/02713683.2016.1259421 